\title{
Does 24-Hour Urine Supersaturation Predict Stone Composition?
}

\author{
Mohamed Omar ${ }^{\mathrm{a}}$, Sarah Tarplin ${ }^{\mathrm{a}}$, Alla El Deen El Mahdy ${ }^{\mathrm{a}}$, Manoj Monga ${ }^{\mathrm{a}, \mathrm{b}}$
}

\begin{abstract}
Background: The aim of the study was to evaluate the correlation between 24-hour urine supersaturation (SS) levels and the crystalline stone composition.

Methods: We retrospectively reviewed the results of stone analysis of 386 patients who had completed 24-hour urine stone risk profiles within 2 months of stone analysis. Patients were characterized as calcium oxalate (CAOX), calcium phosphate (CAPH) or uric acid (UA) stone formers based on the predominant component $(>60 \%)$ of their stone. Patients with $<50 \%$ of one stone composition were characterized as a mixed stone former. Sensitivity, specificity and accuracy of the 24-hour urine SS for predicting the corresponding stone component were calculated.
\end{abstract}

Results: The distribution of stone compositions was $235(61 \%)$ CAOX, 98 (25\%) CAPH, 35 (9\%) UA and 18 (5\%) mixed stone group. At predominant stone mineral concentration $\geq 60 \%$, the accuracy of 24-hour urine SS for predicting the predominant stone composition was $52.5 \%$ for CAOX, $70 \%$ for CAPH and $67 \%$ for UA group. Even when the predominant stone mineral concentration was $\geq 90 \%$, the accuracy of SS did not improve: COAX (49\%, P = 0.6641), CAPH $(77 \%, \mathrm{P}=0.361)$ and $\mathrm{UA}(67 \%, \mathrm{P}=0.9593)$.

Conclusions: Twenty-four-hour urine SS has a poor accuracy to predict the predominant stone composition. Accuracy is highest for patients with $\mathrm{CAPH}$ stones.

Keywords: Supersaturation; $24 \mathrm{~h}$ urine; Stone composition

\footnotetext{
Manuscript accepted for publication March 26, 2015

${ }^{\mathrm{a}}$ Glickman Urological \& Kidney Institute, Cleveland Clinic Foundation, Cleveland, OH, USA

${ }^{\mathrm{b}}$ Corresponding Author: Manoj Monga, Stevan Streem Center for Endourology \& Stone Disease, Glickman Urology \& Kidney Institute, The Cleveland Clinic, 9500 Euclid Avenue, Q10-1, Cleveland, OH 44195, USA.

Email:mongam@ccf.org
}

doi: http://dx.doi.org/10.14740/wjnu206w

\section{Introduction}

It has been suggested that a $24-\mathrm{h}$ urine metabolic evaluation provides the backbone for selection of the most appropriate intervention to prevent stone recurrence [1]. The saturation of urinary salts has been cited for more than four decades as a key risk factor for urolithiasis $[2,3]$.

Supersaturation (SS) is the driving force for crystallization in solutions such as urine [4], defined as the ratio of the concentration of dissolved salt to its solubility [5]. The consequences of increased urinary SS are formation of crystalline particles that is a preface to stone formation, so that the stone composition should reflect the SS averages during the creation and growth of the stone, as such the stone is a type of geological artifact of SS conditions [6]. SSs have also been utilized to monitor response to medical and dietary interventions for stone prevention [7].

In contrast, other theories for stone formation have emerged in the past decade, including the roles of renal tubular damage and cellular dysfunction [8], urinary kidney stone inhibitors and promoters [9], suggesting that SS is not the sole or even predominant risk factor for stone formation [10].

Though a uric acid (UA), cystine or struvite stone composition may direct preventive measures [11], there are cases where the stone composition is unknown (e.g. stones that were removed or passed but were not sent for analysis or patients with stones in the urinary system that have not yet been removed or eliminated) [12].

Our aim was to determine whether 24-hour urine SSs are well correlated with the crystalline component of stones passed by these patients, such that they could serve as a surrogate for stone analysis.

\section{Materials and Methods}

We retrospectively reviewed 386 patients from 2012 to 2014 who completed 24-hour urine stone risk evaluations within 2 months of stone analysis. No dietary or medical preventive measures were initiated in the interval between stone analysis and 24-hour urine evaluation.

Patients were sorted into four groups: calcium oxalate (CAOX), calcium phosphate (CAPH), UA and mixed stones based on the major element of stone component being $\geq 60 \%$.

Articles () The authors | Journal compilation (C) World J Nephrol Urol and Elmer Press Inc ${ }^{\mathrm{TM}}$ | www.wjnu.elmerpress.com This is an open-access article distributed under the terms of the Creative Commons Attribution License, which permits unrestricted use, distribution, and reproduction in any medium, provided the original work is properly cited 
Table 1. Bivariate Comparison of 24-Hour Urine Elements Across Stone Type Groups

\begin{tabular}{llllll}
\hline Demographics & CAOX & CAPH & UA & Mixed & P value \\
\hline $\begin{array}{l}\text { No. of patients (\%) } \\
\text { Gender }\end{array}$ & $235(61 \%)$ & $98(25 \%)$ & $35(9 \%)$ & $18(5 \%)$ & 386 \\
$\quad$ Male & $151(64 \%)$ & $31(32 \%)$ & $24(69 \%)$ & $10(56 \%)$ & $<0.0001$ \\
$\quad$ Female & $84(36 \%)$ & $67(68 \%)$ & $11(31 \%)$ & $8(44 \%)$ & 386 \\
Mean age & $56 \pm 15$ & $54 \pm 17$ & $60 \pm 10$ & $50 \pm 14$ & 0.390 \\
BMI & $29 \pm 7.5$ & $29.3 \pm 9.3$ & $31.2 \pm 6.4$ & $30.5 \pm 7.4$ & 0.3781 \\
pH & $5.9 \pm 0.4$ & $6.4 \pm 0.6$ & $5.8 \pm 0.6$ & $6.4 \pm 0.6$ & $<0.0001$ \\
Urine volume & $2 \pm 0.9$ & $2.1 \pm 1$ & $1.9 \pm 0.8$ & $1.9 \pm 1$ & 0.6195 \\
CAOX SS & $6.74 \pm 3.6$ & $6.6 \pm 3.7$ & $5.9 \pm 3.7$ & $5.6 \pm 3.2$ & 0.3202 \\
CAPH SS & $1 \pm 0.96$ & $1.6 \pm 1.2$ & $0.7 \pm 1.1$ & $1.5 \pm 1.2$ & $<0.0001$ \\
UA SS & $1 \pm 0.87$ & $0.46 \pm 0.5$ & $1.4 \pm 1$ & $0.5 \pm 0.87$ & $<0.0001$ \\
\hline
\end{tabular}

*Stone group: $\geq 60 \%$ of the predominant mineral.

Patients with rare stone types such as cystine and medication-associated stones were excluded.

Stone analyses were performed using Fourier transform infrared spectroscopy and the 24-h urinalyses were performed at Litholink Laboratories (Chicago, IL).

\section{Statistical analysis}

Using Fisher's exact test for categorical data and ANOVA for continuous variables, a comparison between different groups in patient characteristics (including age, sex, height and BMI) and a univariate analysis of 24-h urine variables, across stone type groups were performed using Kruskal-Wallis test for continuous variables and Pearson's Chi-squared test for categorical variables.

Then at different cut-off values of predominant stone com- ponent $(\geq 60 \%, \geq 70 \%, \geq 80 \%$, and $\geq 90 \%)$, we determined sensitivity, specificity and accuracy of the 24-h urine SS for prediction of the corresponding each stone composition, considering the other stone groups as a control.

Patients with 24-h urine more than 2 months from date of stone analysis were excluded.

\section{Results}

Of 386 patients in the study, the mean age was $55 \pm 15$ years, with an average BMI of $29.6 \pm 8.2$. There were $216(57 \%)$ males and $170(43 \%)$ females. We sorted the patients into four groups CAOX, CAPH, UA and mixed stone group based on that the major element of stone component represents $\geq 60 \%$.

The distribution of patients across the three groups and their characteristics are reported in Table 1. The time period

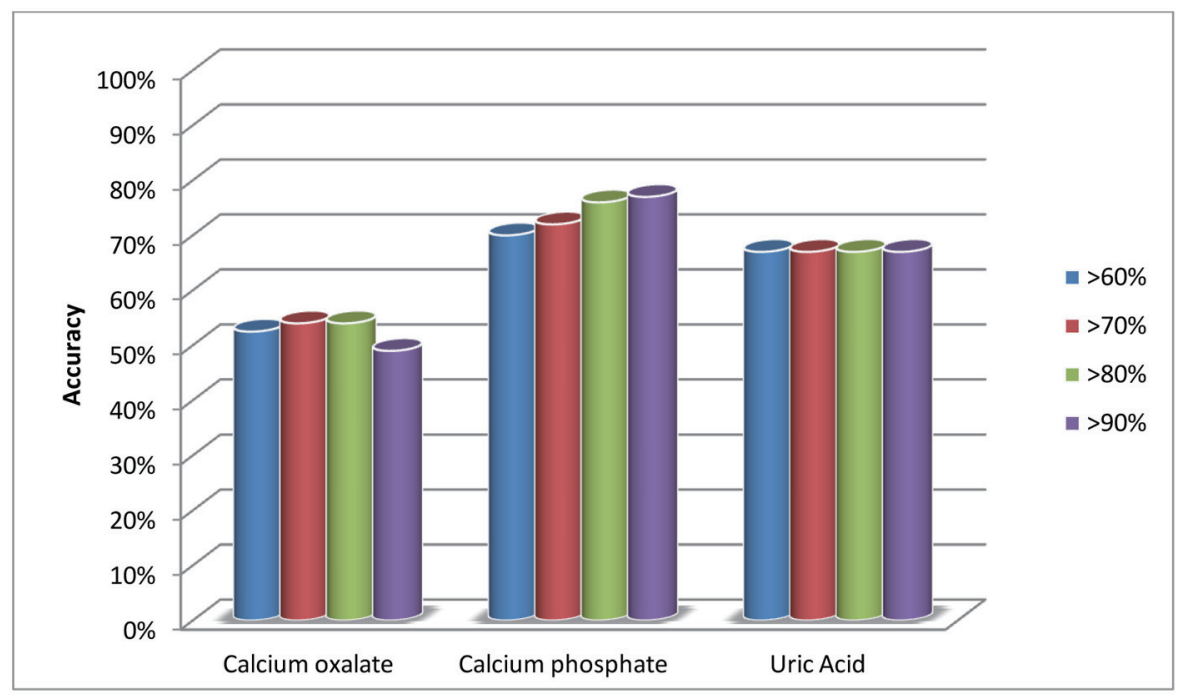

Figure 1. Accuracy of supersaturation at different cut-off values of predominant stone composition. 
Table 2. Accuracy of Supersaturation at Different Cut-Off Values of Predominant Stone

\begin{tabular}{llll}
\hline Mineral stone conc.* (\%) & $\begin{array}{l}\text { Calcium oxalate } \\
\text { (sensitivity/specificity/accuracy) }\end{array}$ & $\begin{array}{l}\text { Calcium phosphate } \\
\text { (sensitivity/specificity/accuracy) }\end{array}$ & $\begin{array}{l}\text { Uric acid } \\
\text { (sensitivity/specificity/ accuracy) }\end{array}$ \\
\hline$>60 \%$ & $54 \% / 51 \% / 52.5 \%$ & $32 \% / 83 \% / 70 \%$ & $60 \% / 67.5 \% / 67 \%$ \\
$>70 \%$ & $55 \% / 50 \% / 54 \%$ & $32 \% / 82.5 \% / 72 \%$ & $60 \% / 67.5 \% / 67 \%$ \\
$>80 \%$ & $55 \% / 52 \% / 54 \%$ & $38 \% / 83 \% / 76 \%$ & $60 \% / 67 \% / 67 \%$ \\
$>90 \%$ & $51 \% / 48 \% / 49 \%$ & $40 \% / 82 \% / 77 \%$ & $60 \% / 67 \% / 67 \%$ \\
\hline
\end{tabular}

${ }^{*}$ Conc.: concentration.

between stone analyses and 24-h urine collection was $25 \pm 35$ days (range 10 - 60 days).

The results of the univariate analysis of patient characteristics (including age, sex, height and BMI) and 24-h urine $\mathrm{SS}$, to detect statistically significant differences in between the three stone groups, are reported in Table 1, showing only significant difference for $\mathrm{CaP}$ and UA SS in relation to other stone groups but not for CAOX SS (Fig. 1).

At predominant stone mineral concentration $\geq 60 \%$, the accuracy of 24-h urine SS for predicting the predominant stone composition was $52.5 \%$ for CAOX, $70 \%$ for $\mathrm{CAPH}$ and $67 \%$ for UA group. Even when the predominant stone mineral concentration was $\geq 90 \%$, the accuracy of SS did not improve: COAX $(49 \%, \mathrm{P}=0.6641)$, CAPH $(77 \%, \mathrm{P}=0.361)$ and UA $(67 \%, \mathrm{P}=0.9593)$ (Table 2).

\section{Discussion}

Urolithiasis is a recurrent condition that is accompanied by significant morbidity. Knowing the stone composition is considered an important step in the prevention of its recurrence. SS is a computed value that indicates the likelihood of crystallization given the concentration of relevant ions and the urinary $\mathrm{pH}[6,13]$.

Several studies have investigated the ability of 24-h urine SS to predict urinary stone composition, suggesting that there is a general concordance between urine SS and stone composition. Despite this, the debate around the importance of SS is still heated $[6,13,14]$. We investigated the accuracy of 24-h $\mathrm{SS}$ in predicting corresponding stone type at different levels of predominant stone composition. Although others have supported the accuracy of SS in the prediction of stone composition, the definition of different stone composition categories used in these studies has been inconsistent. We calculated the $\mathrm{SS}$ accuracy to predict the major stone compositions at increasing percentages of the total stone weight: $60 \%, 70 \%, 80 \%$ or $90 \%$. Accuracy was low, and there was no significant difference in accuracy with increasing levels of the predominant stone composition. Historically, the SS was considered a good predictor for stone type.

In a prospective, controlled study of 585 patients, Parks et al [6] reported a correlation between SS (measured on three separate 24-h urine collections) and stone composition. Further, the study proposed that SS could serve as an index for urinary response to medical therapy. This is in contrast to our findings, which revealed poor accuracy of 24-h urine SS in prediction of predominant stone composition. We cannot comment on the role of 24-h SS in monitoring response to medical therapy, as this was not assessed in our study. Similarly, the utility and specificity of SS in stone management and its implications for pathogenesis of stones was recently questioned by other authors.

In a prospective, controlled study of 538 patients, Lingeman et al elucidated cases of deviation between 24-h urine SS and predominant stone composition, identifying key patterns. In $14 \%$ of their study population, a stone was present but high urinary SS of the main stone constituent was not detected on 24-h urine studies. Conversely, in 19\% of cases (type 1 divergence), 24-h urine SS was high in the absence of a stone. In comparison to our study, these markers for specificity and sensitivity suggest better utility of urinary SS of CAOX, CAPH, and UA in the prediction of stone composition. Of note, this study utilized different cut-off values than ours $(>80 \%$ for $\mathrm{CAOX}),>50 \%$ for $\mathrm{CAPH}$, and pure UA stones, which may have resulted in discrepancies between their results and ours. In addition, problems with sensitivity in prediction of expected composition (type 2 divergence) occurred more commonly in patients with CAOX stones, an observation similar to our study. It is possible that the predictive role of urinary SS is dependent on timing of testing, as temporal stone-related dietary changes can present a distorted picture of the patients' propensity for stone formation. Further, this study is limited by inter-laboratory variability [14]; in our study, the stone analysis was done by single laboratory by infrared spectroscopy and the 24-h urine evaluation was performed by a single laboratory (Litholink, Chicago, IL).

Though the average time between stone analysis and 24-h urine evaluation was short, 2 months, it is certainly feasible that patients may have increased their fluid intake during this interval. A study by Borghi et al [15] of 15 stone-forming patients and 12 controls showed that urine dilution as a result of a water load had the capacity to reduce CAOX SS and increase the urine tolerance to an oxalate load. This suggests that the reliability of different SS formulas on 24-h urine profiles is variable, as it depends on the volume and timing of the collection. Also there was a similar effect of CAOX reduction with water intake among both control and stone-forming groups. This considerable overlap indicates that other mechanism may be involved in stone formation, such as a reduced metastable limit or reduced crystallization inhibitory factors. Although this study highlights some important potential diagnostic limitations of 24-h urine studies, unlike our study, it did not directly examine the correlation between CAOX SS and stone type. 
In a review of 47 studies comparing urinary $\mathrm{SS}$ of stone formers to healthy individuals, Rodgers [16] found that large variability occurred in both groups, such that stone formers could not be distinguished from healthy individuals based on urinary SS. They concluded that it is unfeasible to define a "high" vs. normal SS value; as such, urinary SS has very limited diagnostic value. This is consistent with our findings of low accuracy of urinary SS, even at high cut-off values for predominant stone composition. Further, the authors suggest that the relationship between SS and stone composition may aid only in for the purpose of relative comparisons to track treatment response. While we did not investigate this role, we do currently use SS to monitor response to dietary and pharmacological interventions.

Moreira et al [12] generated a multinomial logistic model to predict stone type from different 24 -h urine variables, including urinary $\mathrm{pH}$, volume, calcium, oxalate, citrate, UA, sodium, potassium, magnesium, phosphorus, sulfate, creatinine, SS CAOX, SS CAPH and SS UA concentrations. This model correctly predicted for CAOX, UA and CAPH, with $64 \%, 68 \%$, and $56 \%$ accuracy, respectively. At $64 \%$, the overall accuracy was not significantly improved as compared to other studies that utilized only urinary SS in the prediction of stone type.

\section{Conclusions}

In conclusion, 24-h urine SS alone does not accurately predict the stone composition.

\section{Grant Support}

None.

\section{Abbreviations}

SS: supersaturation; CAOX: calcium oxalate; CAPH: calcium phosphate; UA: uric acid

\section{References}

1. Coe FL, Parks JH, Asplin JR. The pathogenesis and treatment of kidney stones. N Engl J Med. 1992;327(16):11411152.

2. Coe FL, Parks JH. New insights into the pathophysiology and treatment of nephrolithiasis: new research venues. J
Bone Miner Res. 1997;12(4):522-533.

3. Tiselius HG. Solution chemistry of supersaturation. In: Coe FL, Favus MJ, Pak CYC et al., editors. Kidney Stones: Medical and Surgical Management. Philadelphia: Lippincott-Raven Publishers; 1996. p. 33-64.

4. Aggarwal KP, Narula S, Kakkar M, Tandon C. Nephrolithiasis: molecular mechanism of renal stone formation and the critical role played by modulators. Biomed Res Int. 2013;2013:292953.

5. Lande MB, Varade W, Erkan E, Niederbracht Y, Schwartz GJ. Role of urinary supersaturation in the evaluation of children with urolithiasis. Pediatr Nephrol. 2005;20(4):491-494.

6. Parks JH, Coward M, Coe FL. Correspondence between stone composition and urine supersaturation in nephrolithiasis. Kidney Int. 1997;51(3):894-900.

7. Pearle MS, Goldfarb DS, Assimos DG, Curhan G, Denu-Ciocca CJ, Matlaga BR, Monga M, et al. Medical management of kidney stones: AUA guideline. J Urol. 2014;192(2):316-324.

8. Khan SR. Renal tubular damage/dysfunction: key to the formation of kidney stones. Urol Res. 2006;34(2):86-91.

9. Fleisch H. Inhibitors and promoters of stone formation. Kidney Int. 1978;13(5):361-371.

10. Rao PN. Debate: the key to stone formation is. Urol Res. 2006;34(2):79-80.

11. Kourambas J, Aslan P, Teh CL, Mathias BJ, Preminger GM. Role of stone analysis in metabolic evaluation and medical treatment of nephrolithiasis. J Endourol. 2001;15(2):181-186.

12. Moreira DM, Friedlander JI, Hartman C, Elsamra SE, Smith AD, Okeke Z. Using 24-hour urinalysis to predict stone type. J Urol. 2013;190(6):2106-2111.

13. Fink HA, Wilt TJ, Eidman KE, Garimella PS, MacDonald R, Rutks IR, Brasure M, et al. Medical management to prevent recurrent nephrolithiasis in adults: a systematic review for an American College of Physicians Clinical Guideline. Ann Intern Med. 2013;158(7):535-543.

14. Lingeman J, Kahnoski R, Mardis H, Goldfarb DS, Grasso M, Lacy S, Scheinman SJ, et al. Divergence between stone composition and urine supersaturation: clinical and laboratory implications. J Urol. 1999;161(4):1077-1081.

15. Borghi L, Guerra A, Meschi T, Briganti A, Schianchi T, Allegri F, Novarini A. Relationship between supersaturation and calcium oxalate crystallization in normals and idiopathic calcium oxalate stone formers. Kidney Int. 1999;55(3):1041-1050.

16. Rodgers AL. Urinary saturation: casual or causal risk factor in urolithiasis? BJU Int. 2014;114(1):104-110. 